\title{
Tonic Pupil and Corneal Anesthesia after Vitrectomy and Encircling Band for Retinal Detachment in an Ex-Premature Child
}

\author{
Xavier Valldeperas ${ }^{a} \quad$ Alexandra Arango $^{a} \quad$ Ana Blazquez $^{\mathrm{a}}$ \\ Mario Rosario Romano ${ }^{b}$ \\ aDepartment of Ophthalmology, Hospital Universitari Germans Trias i Pujol, \\ Badalona, Spain; 'bepartment of Ophthalmology, Istituto Clinico Humanitas, \\ Rozzano, Italy
}

\section{Key Words}

Retinal detachment - Retinopathy of prematurity - Encircling band · Laser treatment . Tonic pupil · Corneal anesthesia

\begin{abstract}
An 11-year-old boy presented with a total retinal detachment in his right eye. He had a bilateral $360^{\circ}$ argon laser treatment for an active retinopathy of prematurity performed after his birth. He underwent an uneventful pars plana vitrectomy, encircling band, 810$\mathrm{nm}$ diode endolaser and heavy silicone oil (Densiron ${ }^{\circledR}$ ) endotamponade. A tonic pupil and abolition of corneal sensitivity, with a large epithelial defect, were observed during the postoperative period. We discuss the possible etiopathogenic mechanisms of the long and short ciliary nerves damage, and the role that retinopathy of prematurity and retinal detachment laser treatment and the encircling band placement might have played in the development of the tonic pupil and the corneal anesthesia.
\end{abstract}

\section{Introduction}

Pupil dilatation unresponsive to light stimuli and decreased constriction response to accommodation, with denervation supersensitivity to dilute cholinergic agents, is known as tonic pupil. Most tonic pupil cases are idiopathic, but among all known causes, trauma is the most frequent [1]. It has been described following ocular surgery; there are two classic reports of tonic pupil following retinal detachment $(\mathrm{RD})$ repair, one using an 
encircling band (EB) and another after an old electrocoagulation $[2,3]$, and one recent report after pars plana vitrectomy (PPV) [4].

We describe the onset of a tonic pupil in a child after PPV and EB for a RD. In this case, tonic pupil was associated with total corneal anesthesia after surgery.

\section{Case Report}

An 11-year-old boy attended our emergency department for decreased visual acuity (VA) in his right eye (RE) for the last week. He did not recall any previous trauma. The patient had been a premature newborn, with 26 weeks and $800 \mathrm{~g}$ at birth, and he received a bilateral $360^{\circ}$ argon photocoagulation for active retinopathy of prematurity (ROP). VA, at the emergency room, was hand movement in his RE, with normal anterior segment. Fundoscopy showed a total RD with macula off, and an $180^{\circ}$ inferior giant tear at the posterior edge of the $360^{\circ}$ intense laser scar. The left eye did not show any significant alteration, with an attached retina and a $360^{\circ}$ peripheral laser scar. He underwent a PPV and placement of a $2.5-\mathrm{mm}$ EB and heavy silicone oil (Densiron ${ }^{\circledR}$ ) endotamponade in his RE. A mild infrared laser (810 $\mathrm{nm}$ ) photocoagulation was also performed at the edge of the giant tear. The patient was instructed to position in a supine manner for one week. The retina was successfully reattached (fig. 1). During the immediate postoperative period, he developed a painless persistent corneal epithelial defect $(4 \times 4 \mathrm{~mm})$ in his RE. Corneal sensibility was abolished in this eye. One month after the PPV, the patient was started on intense autologous serum treatment, achieving complete corneal epithelisation within five weeks. When postoperative dilating drops were discontinued a moderate mydriasis in his RE, unresponsive to light, was observed (fig. 2a). No afferent pupillary defect was observed. A positive $0.125 \%$ pilocarpine test confirmed the tonic pupil diagnosis. Four months later, pupil diameter of the RE decreased and a slight anisocoria for right miosis was present (fig. 2c). One year after the PPV, corneal sensibility remains severely decreased and a moderate residual corneal scarring is still present. VA at the present time is $20 / 80$ in his RE.

\section{Comment}

Pupil and accommodation defects have been described following extensive retinal laser treatment [5]. The main explanation for this complication is thermal lesion of the short ciliary nerves, containing parasympathetic motor fibers, travelling through the choroid and suprachoroidal space [6]. Infrared diode laser $(810 \mathrm{~nm})$ produces a much deeper coagulation when compared to argon laser and affects the retinal pigment epithelium and choriocapillaris, and thus easily damages the nerves running in the suprachoroidal area [7].

There are few reports published in the literature, though, on tonic pupil following retinal surgery [2-4]. Newsome et al. [2] report a case of a tonic pupil after EB with lamellar scleral resection and diathermy. They attribute their clinical findings to 'a compromise of the short ciliary nerves as they pass around the globe'. Ebrahim et al. [4] recently published a case after PPV, argon endolaser and silicone endotamponade, performed under retrobulbar anesthesia. They speculate that endolaser damaged the short ciliary nerves and that it is responsible for the tonic pupil. It is surprising, though, that such a small amount of argon laser as described in their case can cause such a serious injury to the short ciliary nerves as to induce a tonic pupil. Nevertheless, they did not rule out a possible causative effect of the retrobulbar anesthesia or even an idiopathic etiology of the case.

Direct injury to the ciliary ganglion by the anesthetic needle can be another cause of tonic pupil onset. There are, to our knowledge, no reports in the literature on this 
etiology. This is not applicable to our case because the patient underwent surgery under general anesthesia.

On the other hand, direct compression of the ciliary ganglion exerted by the EB could be another plausible explanation in our case. Though we believe EB played a role in the development of the tonic pupil, this could be more related to short ciliary nerve damage. EB is usually placed under the rectus muscles, in a much anterior position.

In our case, neural damage following surgery was not restricted to the parasympathetic fibers. Loss of the observed corneal sensibility indicates that sensory fibers might also be affected. The two long posterior ciliary nerves, branches of the nasociliary nerves, are responsible for the sensitivity of the iris, cornea and ciliary muscle. Experimental studies support that parasympathetic fibers travel with the long posterior ciliary nerves proximally, but arborice farther posteriorly near the posterior pole, where the choroid is thickest [8]. Intraocular connections of the long and short ciliary nerves exist within or on the outer surface of the choroid. This suggests that all innervation types can be damaged with an intense laser photocoagulation and that respecting horizontal retinal meridians during the treatment may not always help to preserve these nerves [9].

We hypothesize that there might also be a vascular etiology in the ciliary nerves lesion of our patient. EB has been reported to induce relative ischemia to anterior ocular structures [10] by means of venous obstruction [11] or kinking of the long posterior ciliary arteries [12].

Nevertheless, we cannot rule out that the tonic pupil and corneal anesthesia may arise from the prematurity state and treatments the patient had previously received, especially after observing a slight hypoesthesia of the contralateral cornea.

In conclusion, we believe that a combination of different pathogenic factors have been involved in our case. Thermal injury of the ciliary nerves, initially by the old argon ROP laser and recently by the infrared diode laser for RD repair, combined to the hypothetical blood support deficiency induced by the EB may have resulted in a long ciliary nerves and parasympathetic denervation causing the permanent corneal anesthesia and the tonic pupil.

\section{Disclosure Statement}

The authors declare that they have no conflict of interest. None of the authors has received any grant support or research fund. 


\begin{tabular}{l|l|l|l} 
Case Reports in & $\begin{array}{l}\text { Case Rep Ophthalmol 2010;1:66-70 } \\
\text { DOI: 10.1159/000321250 }\end{array}$ & $\begin{array}{l}\text { Published online: } \\
\text { September 29, 2010 }\end{array}$ & $\begin{array}{l}\text { ○ 2010 S. Karger AG, Basel } \\
\text { ISSN 1663-2699 } \\
\text { www.karger.com/cop }\end{array}$ \\
\hline
\end{tabular}

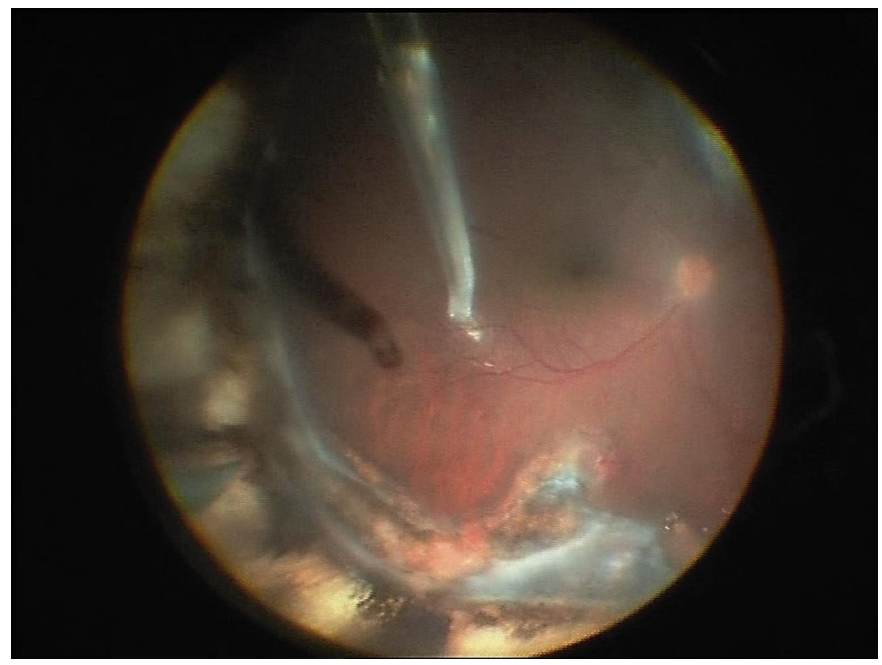

Fig. 1. Fundus photography of the right eye taken during the removal of silicone oil showing a reattached retina with a prominent encircling band indentation and an extensive laser photocoagulation scar.
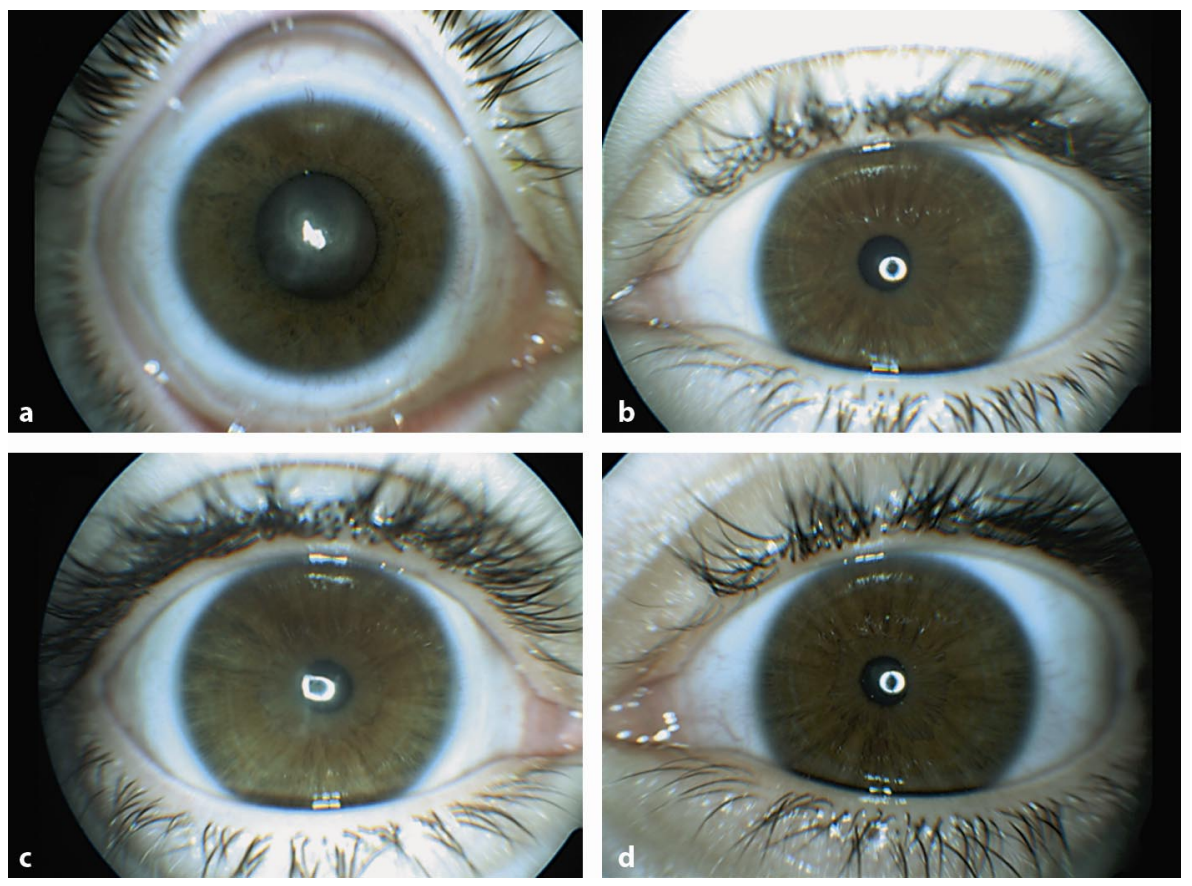

Fig. 2. Pupillary reflexes under direct light examination: moderate mydriasis unresponsive to light in the right eye (a), and normal miosis in the left eye (b), several weeks after the vitrectomy. Four months later, the right pupil decreases its diameter (c). Note the residual central corneal scarring secondary to the healing of the persistent epithelial defect (a and $\mathbf{c}$ ). 


\section{References}

1 Thomson HS: A classification of tonic pupils; in Thomson HS, Daroff RB, Frisen L, et al. (eds): Topics in Neuro-Ophthalmology. Baltimore, Williams and Wilkins, 1979, pp 95-96.

$>2$ Newsome DA, Einaugler RB: Tonic pupil following retinal detachment surgery. Arch Ophthalmol 1971;86:233-234.

-3 Adler FH, Scheie HG: The site of the disturbance in tonic pupils. Trans Am Ophthalmol Soc 1940;38:183-192.

4 Ebrahim B, Frohman L, Zarbin M, Bhagat N: Tonic pupil following pars plana vitrectomy and endolaser. Case Report Med 2009;2009:970502. Epub 2009 Jul 8.

-5 Patel JI, Jenkins L, Benjamin L, Webber S: Dilated pupils and loss of accommodation following diode panretinal photocoagulation with sub-tenon local anaesthetic in four cases. Eye 2002;16:628-632.

6 Lobes LA Jr, Bourgon P: Pupillary abnormalities induced by argon laser photocoagulation. Ophthalmology 1985;92:234-236.

7 Brancato R, Pratesi R, Leoni G, Trabucchi G, et al: Histopathology of diode and argon laser lesions in rabbit retina. IOVS 1989;30:1504-1510.

8 Warwick R: Eugene Wolff s anatomy of the eye and orbit ( $7^{\text {th }}$ Edition). Philadelphia, WB Saunders, 1976, pp $51,62,75,305-313$.

-9 Kaufman PL, Rohen JW: Parasympathetic denervation of the ciliary muscle following panretinal photocoagulation. Curr Eye Res 1991;10:437-455.

10 Lincoff H, Stopa M, Kreissing I, et al: Cutting the encircling band. Retina 2006:26:650-654.

11 Diddie KR, Ernest JT: Uveal blood flow after $360^{\circ}$ constriction in the rabbit. Arch Ophthalmol 1980;98:729730

12 Friedman Z, Neumann E: Effect of retinal detachment surgery on the course of preexisting open-angle glaucoma. Am J Ophthalmol 1975;80:702-705. 